www.jmscr.igmpublication.org

Impact Factor (SJIF): 6.379

Index Copernicus Value: 71.58

ISSN (e)-2347-176x ISSN (p) 2455-0450

crossref DOI:_https://dx.doi.org/10.18535/jmscr/v6i5.11

Journal Of Medical Science And Clinical Research

\title{
A Study of Hypertension and Its Risk Factors among Rural Population in the Field Practice Area of Mahatma Gandhi Medical College and Hospital, Jaipur
}

\author{
Authors \\ Singh Laxman ${ }^{1}$, Bhardwaj SL ${ }^{2 *}$, Sharma BN $^{3}$, Sharma MP ${ }^{4}$, Rathore MS \\ Devanda Lalchand ${ }^{6}$ \\ ${ }^{1,6}$ Resident, ${ }^{2}$ Ex-Professor, ${ }^{3}$ Professor and Head, ${ }^{4,5}$ Professor \\ ${ }^{1-6}$ Department of Community Medicine, Mahatma Gandhi Medical College, Jaipur, Rajasthan, India \\ *Corresponding Author \\ Bhardwaj SL \\ Email:drlaxman2010@gmail.com
}

\begin{abstract}
Background: Hypertension is an important global health issue of the $21^{\text {st }}$ century, which has developed together with rapid economic growth, urbanization, aging population, changing life style and other unhealthy behaviours. The rising burden is big concern especially in rural areas due to unawareness about screening and inadequate approach to health care resources. The present study was planned to measure the prevalence of hypertension and its association with sociodemographic and lifestyle risk factors in rural population of Jaipur.

Material and Methods: This cross sectional, community based study was conducted in the rural field practice area of MGMC, Jaipur. A total 1700 adult participants, aged between 18 to 60 years were enrolled by systemic random sampling method. All the participants were personally contacted in their house, interviewed and examined using predesigned and pretested questionnaire. Baseline data regarding sociodemographic characteristics, behavioural practices and blood pressure were noted down in proforma. $J N C-7$ diagnostic criteria ( $S B P \geq 140 \mathrm{mmHg}$ and/or $\mathrm{DBP} \geq 90 \mathrm{mmHg}$ ) was used for hypertension. Statistical analysis was done by Chi-Square test by using SPSS version 17.

Results: The prevalence of hypertension in our study population was $14.24 \%$. Increasing age, illiteracy, higher SES, sedentary occupation, reduced physical activity, excess intake of salt, family history of hypertension and consumption of tobacco and alcohol were found to be significant risk factor for hypertension.

Conclusion: The prevalence of hypertension among adults in rural field practice area is relatively high. Urgent attention is required to arrest its rising trends, by raising public awareness and identifying it at an early stage and its related factors through primary prevention and further control.

Keywords: Hypertension, rural population, risk factors.
\end{abstract}

\section{Introduction}

Hypertension is an important health issue of the $21^{\text {st }}$ century and one of the major unseen forces behind the global burden of non-communicable diseases (NCDs). Worldwide, 1.39 billion people have hypertension; of these, two thirds are living 
in developing Nations ${ }^{[1-2]}$. The burden is rising and it is likely to increase by $60 \%$ to be 1.56 billion individuals by 2025 and will be 2 fold higher in developing countries ${ }^{[3]}$. India, the world second largest democracy, is under phase of epidemiological transition. Infectious diseases are present on one hand while on one other hand noncommunicable diseases like hypertension is assuming alarming proportions. In fact it is now most common chronic disease and occurrence is high among urban as well rural populations.

The prevalence is quite lower in rural areas but increasing steadily and approaching to the trends as in urban areas, due to profound lifestyle changes including unhealthy consumption of food, substance abuse, sedentary habits without adequate physical activity and other unhealthy behaviours ${ }^{[4]}$. The rising prevalence of hypertension is a big concern especially in rural population because of unawareness about screening and less availability of health care resources. In addition, hypertension is an asymptomatic in the early stage, until its complications develops. In India, where close to $70 \%$ of the population live in rural areas, there is paucity of data regarding hypertension prevalence and its causing risk factors. Therefore, present study was conducted to estimate the prevalence of hypertension and its association with various risk factors in rural population of Vatika, District Jaipur.

\section{Material and Methods}

Study Area: A community based cross-sectional study was conducted among adult's, aged between 18 to 60 years, residing at Vatika Village, which is a Rural Health Training Centre (R.H.T.C) of Department of Community Medicine, Mahatma Gandhi Medical College and Hospital, Sitapura, Jaipur.

Approval from Institutional Ethics Committee (MGMCH/IEC/JPR/2016/316) was taken before commencement of the work. An informed and written consent was obtained from all participants, after complete description of the study and its health benefits. Following which, all the participants of the study were interviewed by using predesigned and pre-tested proforma. Subjects were selected according to their inclusion and the exclusion criteria of the study.

\section{Inclusion Criteria}

- An individual age between 18 to 60 years

- Resident of the Vatika Village

- Willing to participate in the study

\section{Exclusion Criteria}

- An individual age below 18 years and above 60 years

- Any person suffering from acute and chronic illnesses like cardiovascular diseases, chronic kidney diseases etc.

- Person not a permanent resident of Vatika Village

- Females who are pregnant

- Person unwilling to participate in the study in spite of motivation

\section{Study Period}

The study was carried out for a period of 1.5 years from April 2016 to October 2017. The field work was undertaken from September 2016 to February 2017.

\section{Sample Size}

Sample size was calculated by the formula$\mathrm{n}=\mathrm{z}_{\alpha}{ }^{2} \times \mathrm{p} \times \mathrm{q} / \mathrm{d}^{2}$

The prevalence of hypertension among adult population is 22.9 percent ${ }^{[5]}$. By taking prevalence (p) 22.9\% and absolute error (d) 2\%, sample size comes out to be $1695.67 \approx 1700$.

\section{Sampling Method}

Systemic random sampling procedure was used to select the study population. The total population of study place was 10590. The total numbers of houses were 1677 as per Health Survey Register of Local Primary Health Center. After numbering the houses, first house was chosen randomly. Then every alternate house was selected till reached the desired number of samples. 


\section{Study Tool and Variables}

A total 1700 subjects were enrolled in the study. All the subjects were personally contacted in their house, interviewed and examined using predesigned and pretested questionnaire. On visiting the family, baseline data regarding sociodemographic and behavioural practices were noted down in proforma and person aged between 18 to 60 years were screened. Blood pressure was measured in the right upper limb with mercury sphygmomanometer in a sitting position as per standard guidelines. Two reading were taken and average was used for analysis. Diagnosis of hypertension ( $\mathrm{SBP} \geq 140$; $\mathrm{DBP} \geq 90$ ) was made as per the Seventh Report of the Joint National Committee on Prevention, Detection, Evaluation and Treatment of High Blood Pressure (JNC-7) ${ }^{[6]}$.

\section{Operational Definitions}

SES - Modified B.G. Prasad Classification ${ }^{[7]}$ for the year 2015 which is based on per capita income per month in Indian Rupees was used for calculation of socioeconomic status (SES).

Physical Activity- A person was considered physically active if he/she doing 30 minutes of daily brisk walk on most days (5) of the week and physically inactive if he/she not doing any kind of exercise per day.

Dietary Habits: Diet history was noted as stated by subject into vegetarian, non-vegetarian and mixed type. Vegetarian was defined as those who consume cereals, pulses, vegetables, fruits, nuts, milk and milk product. Mixed diet includes eggs, meat in addition to vegetarian diet.

Salt Intake: It was assessed by enquiring whether they had the habit of consuming papad, chutney, pickle or adding extra table salt on the top of cooked food and salad daily.

Tobacco User: Those who were using tobacco products at time of survey in any form either smokeless or smoking tobacco daily or occasionally for at least past one year.

Alcohol User: A person who is taking alcohol at time of study. The amount of alcohol consumed per week (upto $180 \mathrm{ml}$, upto $375 \mathrm{ml}$ or more than
$375 \mathrm{ml}$ ) and duration of consumption were recorded.

Family History of Hypertension: A person was considered to have a family $\mathrm{H} / \mathrm{O}$ hypertension if either one or both the parents of the person had hypertension.

Hypertension: A person was considered hypertensive if -

1. $\mathrm{SBP} \geq 140$ and/or $\mathrm{DBP} \geq 90 \mathrm{mmHg}$

2. Person already on anti-hypertensive treatment

- $\quad$ Normal (SBP $<120 \mathrm{mmHg}$ and DBP $<80 \mathrm{mmHg}$ respectively),

- Pre-hypertension (SBP=120-139 and/or $\mathrm{DBP}=$ 80-89 mmHg),

- Stage I hypertension (SBP=140-159 and/ or DBP $=90-99 \mathrm{mmHg}$ ) and

- $\quad$ Stage II hypertension ( $\mathrm{SBP}=\geq 160$ and $/$ or $\geq 100$ $\mathrm{mmHg}$ )

\section{Statistical Analysis}

Statistical analysis was performed using the SPSS version 17 (SPSS Inc., Version 17, Chicago). Categorical variables were presented in number and percentage. Continuous variables were expressed as mean with standard deviation (SD). Association of hypertension with different variables were analysed by Chi-Square test. Statistical significance was established at $\mathrm{p}<0.05$.

\section{Results}

\section{Sociodemographic Characteristics}

A total 1700 subjects were included in the study. Of these $843(49.59 \%)$ were male and 857 $(50.41 \%)$ were female. Majority of subjects were between age group of 18-25 years (28.24\%). Mean age of the study subjects was $36.82 \pm 13.08$ years. The age wise distribution of the participants was typical of a developing country i.e A large proportion of young people compared to older people.

With regards to literacy, $12.82 \%$ of the subjects were illiterate, followed by primary (11.29\%), middle $(27.76 \%)$, secondary $(23.47 \%)$, higher secondary $(11.23 \%)$ and $13.41 \%$ had completed graduation and above. Majority of them were employed in the agricultural sector or elementary 
jobs such as bus drivers, house painters, electricians, plumber etc.

Regarding religion, $84.18 \%(\mathrm{n}=1431)$ were Hindu, $7.00 \% \quad(\mathrm{n}=119) \quad$ Muslims and 8.82\% $(\mathrm{n}=150)$ belongs to other religion. Most of the subjects were married $(82.82 \%)$ and from nuclear family $(47.18 \%)$. As per modified B.G. Prasad's socioeconomic scale, $80.17 \%(n=1363)$ of the subjects belongs to middle class [upper middle (26.35\%), middle class (30.59\%), lower middle class (17.35\%)], $16.06 \%$ to upper class and $9.65 \%$ to lower class. $15.76 \%(n=268)$ of the subject had family history of hypertension (Table-1).

Table-1 Distribution of study subjects according to Sociodemographic Variables

\begin{tabular}{|c|c|c|c|}
\hline \multirow[t]{2}{*}{ Variables } & Male & Female & Total \\
\hline & $\mathrm{n}(\%)$ & $\mathrm{n}(\%)$ & $\mathrm{n}(\%)$ \\
\hline Age (Mean \pm SD) & $37.12 \pm 13.11$ & $36.53 \pm 13.05$ & $36.82 \pm 13.08$ \\
\hline$\cdot 18-25$ & $230(27.28)$ & $250(29.17)$ & $480(28.24)$ \\
\hline - $26-35$ & $174(20.64)$ & $171(19.95)$ & $345(20.29)$ \\
\hline - $36-45$ & $160(18.98)$ & $170(19.84)$ & $330(19.41)$ \\
\hline - $46-55$ & $145(17.20)$ & $135(15.75)$ & $280(16.47)$ \\
\hline • 56-60 & $134(15.89)$ & $131(15.29)$ & 265 (15.59) \\
\hline \multicolumn{4}{|l|}{ Education } \\
\hline - Illiterate & $98(11.63)$ & $120(14.00)$ & $218(12.82)$ \\
\hline - Primary $\left(5^{\text {th }}\right)$ & $104(12.34)$ & $88(10.27)$ & $192(11.29)$ \\
\hline - Middle $\left(8^{\text {th }}\right)$ & $232(27.52)$ & $240(28.00)$ & $472(27.76)$ \\
\hline - Secondary $\left(10^{\text {th }}\right)$ & $201(23.84)$ & $198(23.10)$ & $399(23.47)$ \\
\hline - Higher sec. $\left(12^{\text {th }}\right)$ & $90(10.68)$ & $101(11.78)$ & $191(11.23)$ \\
\hline - Graduate \& above & 118 (13.99) & $110(12.84)$ & $228(13.41)$ \\
\hline \multicolumn{4}{|l|}{ Occupation } \\
\hline - Unemployed & $113(13.40)$ & $120(14.00)$ & $233(13.71)$ \\
\hline - Unskilled Worker & $110(13.05)$ & $118(13.77)$ & $228(13.41)$ \\
\hline - Semiskilled Worker & $84(9.96)$ & $90(10.50)$ & $174(10.23)$ \\
\hline - Skilled Worker & $80(9.49)$ & $86(10.03)$ & $166(9.76)$ \\
\hline - Clerical/Farmer/Shopkeeper & $222(26.33)$ & $230(26.84)$ & $452(26.59)$ \\
\hline - Semi-Professional & $113(13.40)$ & $111(12.95)$ & $224(13.17)$ \\
\hline - Professional & $121(14.35)$ & $102(11.90)$ & $223(13.12)$ \\
\hline \multicolumn{4}{|l|}{ Marital Status } \\
\hline - Married & $702(83.27)$ & $706(82.38)$ & $1408(82.82)$ \\
\hline - Unmarried & $64(7.59)$ & $55(6.42)$ & $119(7.00)$ \\
\hline - Widower/Divorcee & $77(9.13)$ & $96(11.20)$ & $173(10.18)$ \\
\hline \multicolumn{4}{|l|}{ Religion } \\
\hline - Hindu & $720(85.41)$ & $711(82.96)$ & $1431(84.18)$ \\
\hline - Muslim & $55(6.52)$ & $64(7.47)$ & $119(7.00)$ \\
\hline - Others & $62(7.35)$ & $82(9.57)$ & $150(8.82)$ \\
\hline \multicolumn{4}{|l|}{ Family Type } \\
\hline - Nuclear & $405(48.04)$ & $397(46.32)$ & $802(47.18)$ \\
\hline - Nuclear Ext. & $275(32.62)$ & $286(33.37)$ & $561(33.00)$ \\
\hline - Joint & $163(19.34)$ & $174(20.30)$ & $337(19.82)$ \\
\hline \multicolumn{4}{|l|}{ Socioeconomic Status } \\
\hline - Class I & $138(16.37)$ & $135(15.75)$ & $273(16.06)$ \\
\hline - Class II & $220(26.10)$ & $228(26.60)$ & $448(26.35)$ \\
\hline - Class III & $256(30.37)$ & $264(30.81)$ & $520(30.59)$ \\
\hline - Class IV & $159(18.86)$ & $136(15.87)$ & $295(17.35)$ \\
\hline - Class V & $70(8.30)$ & $94(10.97)$ & $164(9.65)$ \\
\hline \multicolumn{4}{|l|}{ Family H/O HTN } \\
\hline - Yes & 139 (16.49) & $129(15.05)$ & $268(15.76)$ \\
\hline - No & $704(83.51)$ & $728(84.95)$ & $1432(84.24)$ \\
\hline
\end{tabular}

\section{Behavioural Practices}

Among the total study participants, more than half $(53.88 \%, \mathrm{n}=916)$, of the subjects had regular physical activity and rest 784 (46.12) had sedentary life. Majority of the subjects $(73.82 \%)$ were consuming vegetarian diet, $7.65 \%$ non- 
vegetarian diet and rest (18.53\%) were consuming mixed type diet. 66\% $(n=1122)$ of them were taking more than $5 \mathrm{gm}$ salt per day. $54.42 \%(\mathrm{n}=925)$ were taking $10-20 \mathrm{ml}$ fat and $45.59 \%(\mathrm{n}=775)$ were more than $20 \mathrm{ml}$ fat per day.

With regards to substance abuse, $30.94 \%$ were consuming tobacco [either smoking or consuming

Table-2 Distribution of study subjects according to Behavioural Practices

\begin{tabular}{|c|c|c|c|}
\hline \multirow{2}{*}{ Variables } & Male & Female & Total \\
\hline & $\mathrm{n}(\%)$ & $\mathrm{n}(\%)$ & $\mathrm{n}(\%)$ \\
\hline \multicolumn{4}{|l|}{ Physical Activity } \\
\hline - Physical inactive & $398(47.21)$ & $386(45.04)$ & $784(46.12)$ \\
\hline - Physical active & $445(52.79)$ & $471(54.96)$ & $916(53.88)$ \\
\hline \multicolumn{4}{|l|}{ Diet History } \\
\hline - Vegetarian & $615(72.95)$ & $640(74.68)$ & $1255(73.82)$ \\
\hline - Non- Vegetarian & $70(8.30)$ & $60(7.00)$ & $130(7.65)$ \\
\hline - Mixed & $158(18.74)$ & $157(18.32)$ & $315(18.53)$ \\
\hline \multicolumn{4}{|l|}{ Salt Intake } \\
\hline$\bullet$ Less than $5 \mathrm{gm} /$ day & $286(33.93)$ & $292(34.07)$ & $578(34.00)$ \\
\hline - More than $5 \mathrm{gm} /$ day & $557(66.07)$ & $565(65.93)$ & $1122(66.00)$ \\
\hline \multicolumn{4}{|l|}{ Fat Intake } \\
\hline - $10-20 \mathrm{ml}$ & $458(54.32)$ & $467(54.50)$ & $925(54.42)$ \\
\hline •More than $20 \mathrm{ml}$ & $385(45.67)$ & $390(45.50)$ & $775(45.59)$ \\
\hline \multicolumn{4}{|l|}{ Tobacco Consumption } \\
\hline - Yes & $427(50.65)$ & $99(11.55)$ & $526(30.94)$ \\
\hline$\bullet \mathrm{No}$ & $416(49.35)$ & $758(88.45)$ & $1174(69.06)$ \\
\hline \multicolumn{4}{|l|}{ Alcohol Consumption } \\
\hline$\bullet$ Yes & $439(52.07)$ & $46(5.36)$ & $485(28.53)$ \\
\hline$\bullet$ No & $404(47.92)$ & $811(94.63)$ & $1215(71.47)$ \\
\hline
\end{tabular}

\section{Prevalence of Hypertension}

In our study the overall prevalence of hypertension was $14.24 \%$. Grade I hypertension was present in $9.47 \%$ and Grade II in $4.76 \%$ of the subjects. A larger proportion of the study participant's i.e $45.59 \%$ had prehypertension. With regards to smokeless tobacco products (like pan with tobacco or tobacco chewing or pan masala)]. In male $50.65 \%$ were taking tobacco while in female only $11.55 \%$ were taking tobacco. $28.53 \%(\mathrm{n}=485)$ of the them were consuming alcohol. In male $52.07 \%$ were consuming alcohol while in female only $5.36 \%$ were taking alcohol (Table-2).

Table-3 Distribution of study subjects according to Blood Pressure Status

\begin{tabular}{lccc}
\hline $\begin{array}{l}\text { Blood Pressure } \\
(\mathbf{m m H g})\end{array}$ & Male & Female & Total \\
\cline { 2 - 4 } & $\mathrm{n}(\%)$ & $\mathrm{n}(\%)$ & $\mathrm{n}(\%)$ \\
\hline Normal & $380(45.08)$ & $320(37.33)$ & $700(41.18)$ \\
Pre-HTN & $340(40.33)$ & $418(48.77)$ & $758(44.59)$ \\
Hypertension & $123(14.59)$ & $119(13.89)$ & $242(14.24)$ \\
- Stage-I & $86(10.20)$ & $75(8.75)$ & $161(9.47)$ \\
- Stage-II & $37(4.38)$ & $44(5.13)$ & $81(4.76)$ \\
Total & $\mathbf{8 4 3 ( 4 9 . 5 8 )}$ & $\mathbf{8 5 7}(\mathbf{5 0 . 4 1})$ & $\mathbf{1 7 0 0}(\mathbf{1 0 0})$ \\
\hline
\end{tabular}

As shown in Table-4, prevalence of hypertension increased with advancing age; it was $3.75 \%$ in the age group of 18-25 years which gradually increased to $29.43 \%$ in the age group of $56-60$ gender, proportion of hypertension was slightly more in male $(14.59 \%)$ than female $(13.89 \%)$ but the difference was found to be statistically insignificant $(\mathrm{p}>0.05)$ [Table-3]. Out of the 242 hypertensives, $30.16 \%(\mathrm{n}=73)$ were known cases and $69.83 \%(n=169)$ were newly diagnosed cases. 
Table-4 Hypertensive status according to Age

\begin{tabular}{lcccccc}
\hline $\begin{array}{l}\text { Age } \\
\text { (in years) }\end{array}$ & Hypertensive & Normotensive & SBP & DBP & \multirow{2}{*}{$\chi^{2}$} & p-value \\
\cline { 2 - 5 } $18-25$ & $\mathbf{n}(\boldsymbol{\%})$ & $\mathbf{n}(\boldsymbol{\%})$ & $\mathbf{( m m H g )}$ & $\mathbf{( m m H g )}$ & & \\
$26-35$ & $18(3.75)$ & $462(96.25)$ & $109.87 \pm 17.70$ & $74.37 \pm 14.79$ & & \\
$36-45$ & $25(7.24)$ & $320(92.75)$ & $119.13 \pm 17.76$ & $78.02 \pm 17.76$ & & \\
$46-55$ & $53(16.06)$ & $277(83.94)$ & $128.40 \pm 18.76$ & $84.94 \pm 15.34$ & $127.66(4)$ & $p<0.001$ \\
$56-60$ & $68(24.28)$ & $212(75.71)$ & $134.86 \pm 10.86$ & $86.30 \pm 16.93$ & & \\
Total & $78(29.43)$ & $187(70.57)$ & $138.62 \pm 15.64$ & $87.12 \pm 17.53$ & & \\
& $\mathbf{2 4 2}(\mathbf{1 2 . 4 2})$ & $\mathbf{1 4 5 8}(\mathbf{8 5 . 7 6})$ & $\mathbf{1 2 4 . 7 5} \pm \mathbf{1 7 . 9 8}$ & $\mathbf{8 1 . 5 8} \pm \mathbf{1 6 . 5 6}$ & & \\
\hline
\end{tabular}

Table-5 shows that prevalence of hypertension was high in illiterate subjects $(19.72 \%)$, than who were educated up to primary $(17.71 \%)$, middle $(13.14 \%)$, secondary (12.03\%), higher secondary (8.90\%), and had received education up to graduate and above (16.67\%).As per socioeconomic status, hypertension was quite more common in the subjects belongs to upper socioeconomic class, compared to lower socioeconomic class. The difference was found to be statistically significant $(p<0.05)$.

The occurrence of hypertension in subjects with sedentary occupation such as professionals, senior

Table-5 Hypertension with Sociodemographic Characteristics

\begin{tabular}{|c|c|c|c|c|c|}
\hline Variables & $\begin{array}{l}\text { Total } \\
\text { n(\%) }\end{array}$ & $\begin{array}{c}\text { Hypertensive } \\
\text { n (\%) }\end{array}$ & $\begin{array}{c}\text { Normotensive } \\
\mathrm{n}(\%)\end{array}$ & $\chi^{2}$ & $p$-value \\
\hline \multicolumn{6}{|l|}{ Education } \\
\hline Illiterate & $218(12.82)$ & $43(19.72)$ & $175(80.28)$ & & \\
\hline Primary & $192(11.29)$ & $34(17.71)$ & $158(82.29)$ & & \\
\hline Middle & $472(27.76)$ & $62(13.14)$ & $410(86.86)$ & $14.89(5)$ & $P<0.05$ \\
\hline Secondary & $399(23.47)$ & $48(12.03)$ & $351(87.97)$ & & \\
\hline Higher Sec & $191(11.23)$ & $17(8.90)$ & $174(91.10)$ & & \\
\hline Graduate \& above & $228(13.41)$ & $38(16.67)$ & $190(83.33)$ & & \\
\hline \multicolumn{6}{|l|}{ Occupation } \\
\hline Unemployed & $233(13.71)$ & $41(17.60)$ & $192(82.40)$ & & \\
\hline Unskilled worker & $228(13.41)$ & $34(14.91)$ & $194(85.09)$ & & \\
\hline Semi Skilled worker & $174(10.23)$ & $21(12.07)$ & $153(87.93)$ & $16.77(6)$ & $P<0.05$ \\
\hline Skilled worker & $166(9.76)$ & $21(12.65)$ & $145(87.35)$ & & \\
\hline Farmer & $452(26.59)$ & $44(9.73)$ & $408(90.27)$ & & \\
\hline Semi-professional & $224(13.17)$ & $38(16.96)$ & $186(83.04)$ & & \\
\hline Professional & $223(13.12)$ & $43(19.28)$ & $180(80.72)$ & & \\
\hline \multicolumn{6}{|l|}{ Marital Status } \\
\hline Married & 1408 (82.82) & $204(14.49)$ & $1204(85.51)$ & & \\
\hline Unmarried & $119(7.00)$ & $10(8.40)$ & $109(91.59)$ & $3.93(2)$ & $P>0.05$ \\
\hline Widower/divorcee & $173(10.18)$ & $28(16.18)$ & $145(83.82)$ & & \\
\hline \multicolumn{6}{|l|}{ Religion } \\
\hline Hindu & $1431(84.17)$ & $207(14.46)$ & $1224(85.53)$ & & \\
\hline Muslim & $119(7.00)$ & $17(14.28)$ & $102(85.71)$ & $3.66(2)$ & $P>0.05$ \\
\hline Others & $150(8.82)$ & $18(12.00)$ & $132(88.00)$ & & \\
\hline \multicolumn{6}{|l|}{ Type of Family } \\
\hline Nuclear & $802(47.18)$ & $124(15.46)$ & $678(84.54)$ & & \\
\hline Nuclear Ext. & $561(33.00)$ & $79(14.08)$ & $482(85.91)$ & $2.99(2)$ & $\mathrm{P}>0.05$ \\
\hline Joint & $337(19.82)$ & $39(11.57)$ & $298(88.43)$ & & \\
\hline \multicolumn{6}{|l|}{ Socioeconomic Status } \\
\hline Upper Class I & $273(16.06)$ & $54(19.78)$ & $219(80.22)$ & & \\
\hline Upper Middle Class II & $448(26.35)$ & $71(15.85)$ & $377(84.15)$ & & \\
\hline Middle Class III & $520(30.59)$ & $60(11.54)$ & $460(88.46)$ & $13.05(4)$ & $P<0.05$ \\
\hline Lower Middle Class IV & $295(17.35)$ & $40(13.55)$ & $255(86.44)$ & & \\
\hline Lower Class V & $164(9.65)$ & $17(10.36)$ & $147(89.63)$ & & \\
\hline \multicolumn{6}{|l|}{ Family H/O HTN } \\
\hline Yes & $268(15.76)$ & $53(19.78)$ & $215(80.22)$ & & \\
\hline No & $1432(84.24)$ & $189(13.20)$ & $1243(86.80)$ & $8.00(1)$ & $P<0.01$ \\
\hline
\end{tabular}


As illustrated in table-6, more than half $(53.71 \%$; $\mathrm{n}=130$ ) of the hypertensive subjects were engaged in regular physical activity. Majority of them $(72.31 \%, \mathrm{n}=175)$ were consuming more than $5 \mathrm{gm}$ salt per day. The prevalence of hypertension was significantly high in subjects who were physically inactive $(p<0.05)$ and taking excess amount of salt per day (>5 gm/day; $p<0.05)$.In hypertensives, nearly $1 / 3^{\text {rd }}$ of the subjects $(34.71 \% ; n=84)$ were consuming alcohol. The prevalence of hypertension in alcohol users was $17.32 \%$ and in non users it was 13.0 percent. Out of the 242 hypertensives, $38.02 \%(\mathrm{n}=92)$ of the subjects were either smoking tobacco or consuming smokeless tobacco products .The occurrence of hypertension in tobacco users was $17.49 \%$ and in non users it was $12.78 \%$. A significant association of hypertension was observed with tobacco $(p=0.010)$ and alcohol consumption $(p=0.021)$. As per dietary habits of the hypertensive subjects, majority were found to consume vegetarian diet $182(75.21 \%)$, and taking $10-20 \mathrm{ml}$ fat per day $(52.48 \% ; \mathrm{n}=127)$. However, our study did not reveal any significant association of hypertension with dietary habits and fat intake of the subjects $(p>0.05)$.

Table-6 Hypertension with Behavioural Characteristics

\begin{tabular}{|c|c|c|c|c|c|}
\hline Variables & $\begin{array}{l}\text { Total } \\
\text { n( } \%)\end{array}$ & $\begin{array}{c}\text { Hypertensive } \\
\mathrm{n}(\%)\end{array}$ & $\begin{array}{c}\text { Normotensive } \\
\mathrm{n}(\%)\end{array}$ & $\chi^{2}$ & p-value \\
\hline \multicolumn{6}{|l|}{ Physical Activity } \\
\hline Yes & $784(46.12)$ & $130(16.58)$ & $654(44.85)$ & $6.56(1)$ & $P<0.05$ \\
\hline No & $916(53.88)$ & $112(12.22)$ & $804(55.14)$ & & \\
\hline \multicolumn{6}{|l|}{ Visible Salt Intake } \\
\hline Less than 5 & $578(34.00)$ & $67(11.59)$ & $511(88.41)$ & $5.01(1)$ & $P<0.05$ \\
\hline More than 5 & $1122(66.00)$ & $175(15.60)$ & $947(84.40)$ & & \\
\hline \multicolumn{6}{|l|}{ Dietary Habits } \\
\hline Vegetarian & $1255(73.82)$ & $182(14.50)$ & $1073(85.49)$ & & \\
\hline Non-Vegetarian & $130(7.65)$ & $10(7.69)$ & $120(92.31)$ & $5.32(2)$ & $P>0.05$ \\
\hline Mixed & $315(18.53)$ & $50(15.87)$ & $265(84.13)$ & & \\
\hline \multicolumn{6}{|l|}{ Fat Intake/day } \\
\hline $10-20 \mathrm{ml}$ & $925(54.42)$ & $127(13.73)$ & 798 (86.27) & $0.42(1)$ & $P>0.05$ \\
\hline More than $20 \mathrm{ml}$ & 775 (45.59) & $115(14.84)$ & $660(85.16)$ & & \\
\hline \multicolumn{6}{|l|}{ Alcohol } \\
\hline \multicolumn{6}{|l|}{ Consumption } \\
\hline Yes & $485(28.53)$ & $84(17.32)$ & $401(82.68)$ & $5.18(1)$ & $P<0.05$ \\
\hline No & $1215(71.47)$ & $158(13.00)$ & 1057 (86.99) & & \\
\hline \multicolumn{6}{|l|}{ Tobacco } \\
\hline \multicolumn{6}{|l|}{ Consumption } \\
\hline Yes & $526(30.94)$ & $92(17.49)$ & $434(82.51)$ & $6.61(1)$ & $P<0.05$ \\
\hline No & $1174(69.05)$ & $150(12.78)$ & $1024(87.22)$ & & \\
\hline
\end{tabular}

\section{Discussion}

In the present study, overall prevalence of hypertension was $14.24 \%$. In hypertensives, $50.82 \%(n=123)$ were male and $49.18 \%(n=119)$ were female. Grade-I hypertension was present in $9.47 \%$ while grade II in $4.76 \%$ of subjects. $44.59 \%$ of participants had pre-hypertension. Out of the 242 hypertensives, $69.83 \%$ of the cases were newly diagnosed and $30.16 \%$ were known cases.

Findings of our study are comparable to data obtained by Gupta $\mathrm{R}$ et $a l^{[8]}$ in his study titled "Trends in hypertension epidemiology in India" where the prevalence of hypertension has been reported to range between 12 to $17 \%$ among rural adults in Rajasthan, India. However, observations were differed from those given by the office of the Register General of India (10.0\%) and WHO $(22.6 \%)^{[9,10]}$.

Study by Parekh A et al $(20.40 \%)^{[11]}$, Basu G and Biswas S $(21.90 \%)^{[12]}$, Yuvaraj BY et al $(18.30 \%)^{[13]}$, Pooja and Mittal Y $(33.20 \%)^{[14]}$ and Meshram II et al $(40 \%)^{[15]}$ reported higher prevalence of hypertension in rural population of India while Rao PC et al $(4.89 \%)^{[16]}$, Madhukumar S et al $(8.06 \%)^{[17]}$, and Thrift AG et 
al $(11.40 \%)^{[18]}$ showed lower prevalence. This disparity in results might be due to the difference in methodology, age range of the participants, dissimilar lifestyle and variations in socioeconomic status, genetic make-up and biological diversity.

The prevalence of hypertension was found to be steadily increased with age. Lowest prevalence (3.75\%) was seen in 18-25 years of age group which rose to $29.43 \%$ in 56 to 60 years of age group and the difference was statistically significant $\left(\chi^{2}=127.66 ; p<0.001\right)$. The gradual increase in prevalence of hypertension with age is well documented. The main reason is that arteries and arterioles become less elastic due to atherosclerotic changes as people age. Changes in lifestyle, physical inactivity, stress, accumulation of environmental influences and the effects of genetically programmed senescence in body system are also important contributors ${ }^{[19]}$. Singh PS et $\mathrm{al}^{[20]}$ observed 5.26 times higher prevalence among the older age group (more than 50 years of age) than $6.3 \%$ in individuals with less than 30 years of age and $18.1 \%$ in 30-50 years of age group in rural population of India. Ismail MM et $a l^{[21]}$ in a comparative study of hypertension among urban and rural population of South India found $6 \%$ prevalence of hypertension in the age group of 20 to 29 years, which increased to $52.4 \%$ for people of aged $\geq 70$ years.

Gender wise, proportion of hypertension was more in males (14.59\%) compared to females $(13.89 \%)$ but statistically insignificant $(p>0.05)$. Gupta $\mathrm{R}$ et $a l^{[8]}$ in Rajasthan, Mohan V et al ${ }^{[22]}$ in Chennai and Ismail MM et al $^{[21]}$ in a coastal town of South India found high proportion of hypertension in Males. Similar results were also observed by Wasnik VR et al ${ }^{[23]}$ (14.3\% among males and $12 \%$ in females ). So, it is clear that in some regions of India hypertension is more prevalent among males than females.

The prevalence of hypertension according to education did not show a specific pattern of distribution. We found higher prevalence of hypertension in illiterate subjects (19.72\%), followed by individuals educated up to primary $(17.71 \%)$ and then in individuals educated up to graduation and above (16.67\%). Lower prevalence was seen in individuals educated up to higher secondary school level $(8.90 \%)$ than in individuals educated up to secondary (12.03\%) and middle school level (13.14\%), but difference was found to be statistically significant $\left(\chi^{2}=14.89 ; p=0.010\right)$. Higher prevalence of hypertension among the illiterate subjects indirectly shows the lack of awareness of the people about screening or may be due to other unhealthy behaviours. The Jaipur rural study ${ }^{[24]}$ had also reported a higher prevalence among illiterate or low education peoples. Similar results were observed by Verma $\mathrm{M}$ et $a l^{[25]}$ in rural population of North India (34.4\%) and Sharma AK et $a l^{[26]}$ among desert based rural population of Rajasthan.

In the present study, hypertension was more prevalent in upper socioeconomic class (19.78\%) as compared to lower socioeconomic class $(10.36 \%)$. The difference was statistically significant $\quad\left(\chi^{2}=13.05 ; \quad p<0.05\right)$. In upper socioeconomic class, higher prevalence of hypertension may be due to high rates of obesity, lack of physical activity, type of occupation and high mental stress. Our results are comparable with study done by Verma $\mathrm{M}$ et $a l^{[25]}$, which showed that prevalence of hypertension was higher in upper SEC (42.9\%) than lower SEC $(12.4 \%)$. Similar findings have been reported in rural populations of Sitapura by Kumar $\mathrm{K}$ et al ${ }^{\text {[27] }}$, Kokiwar PR et al ${ }^{[28]}$ in rural community of central India and Rajasker VD et $a l^{[29]}$ in rural area of Tamil Nadu .On the contrary, there are some studies that show that in many population, hypertension is more prevalent in the lower SEC, especially in the underdeveloped countries. In a national study by cardiology society of India, no such differences were observed between high and low SE groups ${ }^{[30]}$.

Subjects with sedentary occupations such as managers, senior officials, retired persons, housewives, and professionals had a higher prevalence of hypertension compared to non- 
sedentary occupations such as farmers, maids, dhobis, daily wage workers, coolie, carpenter, plumber and house painters. The difference was found to be statistically significant $\left(\chi^{2}=16.77\right.$; $p=0.010)$. Similar results were also observed by Rajasekar VD et al ${ }^{[29]}$ in Puducherry, India where they found that people involved in sedentary occupations were at an increased risk of developing hypertension compared to those in non-sedentary occupations.

In our study, majority of the hypertensive subjects (84.29\%) were married belongs to religion Hindu $(85.54 \%)$, and from (51.24\%) nuclear family. However, we did not found any association between marital status, religion, types of family and subsequent development of HTN ( $p>0.05)$. Among hypertensives, $21.90 \%$ of the subjects had a family history of hypertension. The occurrence of hypertension was significantly higher $\left(\chi^{2}=8.00\right.$; $p=0.004$ ) in subjects who had family history of hypertension (19.78\%) than who did not (13.20\%).Family history of hypertension is a major risk factor for development of hypertension and several epidemiological studies have reported that 20-60 percent of essential hypertension is inherited and rest is acquired or environmental. In addition, Genetic studies have reported a polygenic inheritance of hypertension. Deswal BS et al $^{[31]}$ found 4.86 times more risk of developing hypertension in $1^{\text {st }}$ degree relatives as compared to those who did not have the family history.

Regarding behavioural habits of the hypertensive subjects, the occurrence of hypertension in physically inactive subjects was $(16.58 \%)$ more than in active subjects $(12.22 \%) \quad\left(\chi^{2}=6.56\right.$; $p<0.05)$. Jajoo UN et al ${ }^{[32]}$ observed that moderate and light activity population is more prone to have hypertension (1.49 times in male and 1.69 times female) compared to population engaged in heavy physical activity. Sedentary individuals have 20 to 50 percent increased risk of developing hypertension $^{[33]}$. Satheesh BC et al ${ }^{[34]}$, Bartwal J et al ${ }^{[35]}$, Verma $\mathrm{M}$ et al ${ }^{[25]}$, Kokiwar PR et al ${ }^{[28]}$ and Ismail MM et al ${ }^{[21]}$ found reduced physical activity, to be a significant risk factors of hypertension.

The prevalence of hypertension in subjects consuming mixed diet was $15.87 \%, 14.50 \%$ in vegetarian subjects and $7.69 \%$ in non-vegetarians. We did not found any significant association between hypertension and dietary habits of subjects $\left(\chi^{2}=5.32 ; p>0.05\right)$. As per fat intake per day, $52.48 \%$ of the hypertensive subjects were consuming $10-20 \mathrm{ml}$ fat and $47.52 \%$ of the subjects were taking more than $20 \mathrm{ml}$ fat per day. The prevalence of hypertension was $14.84 \%$ in hypertensives consuming more than $20 \mathrm{ml}$ par day and $13.73 \%$ in subjects consuming less than $20 \mathrm{ml}$ per day. Our study did not reveal any significant association between fat intake and hypertension $\left(\chi^{2}=0.425 ; p>0.05\right)$.

A higher prevalence was observed in hypertensives taking more than $5 \mathrm{gm}$ salt per day (15.60\%), compared to taking less than $5 \mathrm{gm}$ salt per day (11.59\%). Excess salt intake was found to be a significant risk factor for the development of hypertension $\left(\chi^{2}=5.013 ; p=0.025\right)$. Sodium is predominantly an extracellular cation and is a primary determinant of extracellular fluid volume (ECF). Sodium excretion is regulated by kidney and when its intake exceeds the capacity of kidney to excrete, initially vascular volume expands and cardiac output increases, which in turn increases the blood pressure.In a study on sodium intake and blood pressure in healthy individuals Ducher $\mathrm{M}$ et al ${ }^{[36]}$ found that 5 to 16 percent of healthy persons have salt dependent blood pressure and many more benefited from decrease dietary intake of salt.In the INTERSALT international study ${ }^{[37]}$, high intake of salt was found a risk factor for the development of hypertension.

In our study, prevalence of hypertension in tobacco users was $17.49 \%$ and in non users it was $12.78 \%$. In tobacco users, $60.86 \%(\mathrm{n}=56)$ were consuming tobacco products while $39.13 \%(n=36)$ were smoking tobacco. Most of the tobacco smokers, smoked predominantly beedi $(77.77 \%$; $\mathrm{n}=28)$ and the rest $22.22(\mathrm{n}=8)$ smoked cigarettes. A significant association was found between 
tobacco consumption and hypertension $\left(\chi^{2}=6.61\right.$; $p=0.010$ ). Tobacco smoke mainly contains nicotine and various toxic substances such as acetone, benzene, carbon monoxide, and hydrogen cyanide, all of these causes vasoconstriction which may increase the blood pressure. In a recent study by Ismail MM et $a l^{[21]}$, smokeless tobacco consumption was found a predominant risk factor for hypertension in the rural population of Karnataka, South India.

In the present study, $34.71 \% \quad(n=84)$ of the hypertensives were consuming alcohol. Among alcoholics $22.61 \%(\mathrm{n}=19)$ were taking $<180 \mathrm{ml}$ per day, $47.62 \%(\mathrm{n}=40)$ were up to $375 \mathrm{ml}$ and $29.76 \%$ $(\mathrm{n}=25)$ were more than $375 \mathrm{ml}$ of alcohol per day. The prevalence of hypertension in alcohol users was $17.32 \%$ and in non users it was $13.00 \%$. We observed a significant association in alcohol consumption and hypertension $\quad\left(\chi^{2}=5.18\right.$; $p=0.021)$. The mechanisms by which alcohol causes elevation of blood pressure include a direct pressure effect of alcohol on the vessel wall, a sensitization of resistance vessels to presser substances, stimulation of sympathetic nervous system, and increased production of adrenocorticoid hormones ${ }^{[38]}$.In a study among rural population of coastal town in South India, Ismail MM et $a l^{[21}$ found 1.73 times odds of developing hypertension among those consuming alcohol than that of non-alcoholics. Similar findings were observed by Dhungana RR et al ${ }^{\text {[39] }}$ in recent study in Municipalities of Kathmandu, Nepal.

\section{Conclusion}

The prevalence of hypertension (14.24\%) and prehypertension $(44.59 \%)$ was higher in rural population of Vatika, District Jaipur, Rajasthan. Lifestyle related modifiable risk factors like, physical inactivity, excess intake of salt, consumption of tobacco and alcohol were found to be significantly associated with hypertension. This suggests that there is a significant scope to create awareness about the adverse effects of these multiple lifestyle habits. Community based approaches for reduction of hypertension and its preventable risk factors should be started. Early screening as well as preventive and control strategies should be effectively used to reduce prevalence of hypertension and morbidity and premature mortality from hypertension.

\section{References}

1. Bloch MJ. Worldwide prevalence of hypertension exceeds 1.3 billion. Journal of American society of hypertension. 2016;10(10):753-754.

2. Mills KT, Bundy J., Kelly TN, Reed JE, Kearney PM, Reynolds K et al. Global disparities of hypertension prevalence and control: a systematic analysis of population based studies from 90 countries. Circulation. 2016; 134:441-450.

3. Lewington S, Clarke R, Qizilbash $\mathrm{N}$ et al. Age specific relevance of usual blood pressure to vascular mortality: A metaanalysis of individual data for one million adults in 61 prospective studies. Lancet. 2002;360:1903-13.

4. Anchala R, Kannuri NK, Pant H, Khan H, Oscar H, Franco OH, Emanuele Di, Angelantonio ED and Prabhakaran D. Hypertension in India: a systematic review and meta-analysis of prevalence, awareness, and control of hypertension. J Hypertens. 2014 Jun; 32(6): 1170-1177.

5. World Health Organization. A Global Brief on Hypertension: Silent Killer, Global Public Health Crisis. World Health Day 2013. Report, 1-39. Geneva, Switzerland: World Health Organization; 2013.

6. The seventh report of the joint national committee on prevention, detection, evaluation, and treatment of high blood pressure: The JNC 7 Report. JAMA. 2003; 289: 2560-72.

7. Abha Mangal et al. Modified B.G. Prasad classification for the year 2015. Indian 
Journal of Public Health. 2015;59(1):4244.

8. Gupta R. Trends in Hypertension epidemiology in India. Journal of Human Hypertension. 2004;18:73-78.

9. World Health Organization. World Health Statistics 2014. Geneva: WHO; 2014. Available from: http://www.who.int/gho/publications/ world_health__statistics/2014/en/. [Last accessed on 2017 Jul 23].

10. Report on Causes of Deaths in India 20012003. New Delhi: Office of the Registrar General of India, Govt. of India; 2010. p. 42-5.

11. Parekh A, Parekh M, Vadasmiya D, Kumar A. Study of Prehypertension \& Hypertension in rural area of Vadodara district. Int $\mathrm{J}$ Med Sci Public Health 2013;2(1):117-20.

12. Basu G, Biswas S. Epidemiology of Hypertension and its risk factors in a village of West Bengal. Indian Journal of research and reports in Medical Sciences. 2013;3:24.

13. Yuvaraj BY, Nagendra GMR. Umakantha AG. Prevalence, awareness, treatment and control of hypertension in rural area of Davanagere. Indian Journal of Community Medicine. 2010;35(1):13841.

14. Pooja and Mittal Y. Prevalence of hypertension among rural population of Doiwala Block, Dehradun, Uttarakhand, India. Recent Research in Science and Technology. 2013;5(1):21-24.

15. Meshram II, Laxmaiah A, Mallikharjun RK, Arlappa N, Balkrishna N, Reddy CG et al. Prevalence of hypertension and its correlates among Adult Tribal Population ( $\geq 20$ years) of Maharashtra state, India. International Journal of Health Sciences and Research. 2014;4(1):130-139.

16. Rao PC, Venkatramana P, Annaiah P, and Reddy PC. Prevalence and predictors of hypertension in an ethnic population of
South India. Anthropologist.2013; 15: 193-197.

17. Madhukumar S, Gaikwad V, Sudeepa D. An epidemiological study of hypertension and its risk factors in rural population of Bangalore rural district. Al Ameen Journal of Medical Sciences. 2012;3:264-70. 20.

18. Thrift AG, Evans RG, Kalyanram K, Kartik K, Fitzgerald SM, Srikant V. Gender-specific effects of caste and salt on hypertension in poverty: A population based study. Journal of Hypertension. 2011;29(3):443-50. 21.

19. World Health Organization. Hypertension control. Geneva, Switzerland: World Health Organization; TRS 862, 1996.

20. Singh PS, Singh PK, Zafar KS and Sharma $\mathrm{H}$ et al. Prevalence of hypertension in rural population of central India. International Journal of Research in Medical Science. 2017;5(4):1451-1455.

21. Ismail MM, Kulkarni AG, Meundi AD and Amruth M. A community based comparative study of prevalence and risk factors of hypertension among urban and rural populations in a costal town of south India. Sifa Medical Journal. 2016; 3: 4147.

22. Mohan V, Deepa M, Farooq S, Datta M, Deepa R. Prevalence, awareness and control of hypertension in Chennai: the Chennai Urban Rural Epidemiology Study (CURES-52). J Assoc Physic India 2007;55:326-32.

23. Wasnik VR and Jawarkar. Prevalence of hypertension and pre-hypertension in rural area of Amravati District of Maharashtra, India. International Journal of Research in Medical sciences. 2016; Feb 4(2): 549555.

24. Gupta R, Sharma AK. Prevalence of hypertension and sub type in an Indian rural population: Clinical and Electrocardiographic Correlates. J Human Hypertension. 1994; 8:823-829. 
25. Verma M, Rajput M, Sahoo SS, Kaur N, Rohilla R and Sharma R. Prevalence of hypertension and its association with different anthropometric variables among adult in rural areas of North India. International Journal of Research and Pharmacy and Life Sciences. 2015;4(5):1775-1783.

26. Sharma AK Gupta VP, Prakash H, Bharadwaj H, Gupta R. High prevalence of hypertension in the desert based population of Rajasthan. South Asian Journal of Preventive Cardiology. 2003;7(2):81-89.

27. Kumar K, Kothari RP, Kothari K, Garg S, Khandelwal MK, and Gupta R. Prevalence of hypertension in an urban and rural area of Jaipur district. International Journal of healthcare and Biomedical Research. 2013;1:120-126.

28. Kokiwar PR, and Gupta SS. Prevalence of Hypertension in a rural community of Central India. International Journal of Biomedical Research. 2011;2: 950-953.

29. Rajasekar VD, Krishnagopal L, Mittal A, Singh Z, Purty AJ, Binu VS. Prevalence and risk factors for hypertension in a rural area of Tamil Nadu, South India. Indian J Med Specialties. 2012;3:12-7. 25.

30. Gupta R, Gupta KD. Coronary heart disease in low socioeconomic status subjects in India: "An evolving epidemic". Indian Heart J. 2009;61:358-67.

31. Deswal BS et al. An epidemiological study of hypertension among residents in Pune. Indian Journal of Community Medicine.1991;16(1):21-28.

32. Jajoo UN, Kalanatri SP, Gupta OP, and Jain AP. The prevalence of hypertension in rural population around Sewagram. Journal of Association of Physicians of India.1993; 41, 422-424.
33. Blair SN, Goodyear NN, Gibbons LW, Cooper KH. Physical fitness and incidence of hypertension in healthy normotensive men and women. Journal of American Medical Association.1984;252:487-490.

34. Satheesh BC and Mohammad Iliyas C. Prevalence of hypertension in a rural community of North Kerala, India: A cross sectional study. Int $\mathbf{J}$ of Community Medicine and Public Health. 2017;4(2): 528-531.

35. Bartwal J, Awasthi S, Rawat CMS and Singh RK. Prevalence of hypertension and its risk factors among individuals attending outpatient department of rural health training centre, Haldwani. Indian Journal of Community Health. 2014; 26(1):76-81.

36. Ducher M, Fauvel JP, Maurin M et al. Sodium intake and blood pressure in healthy individuals. $\mathrm{J}$ of Hypertension. 2003; 21: 289-294.

37. Stalmer R. Implications of the INTERSALT study. Hypertension. 1991;17 (Suppl): I16-20.

38. Anand MP. Epidemiology and Current Concepts in Hypertension. 2nd ed. Mumbai, India: ICP; 1995. p. 4-13.

39. Dhungana RR, Pandey AR, Bista B, Joshi S, and Devkota S. Prevalence and Associated Factors of Hypertension: A Community-Based Cross-Sectional Study in Municipalities of Kathmandu, Nepal. International Journal of Hypertension. 2016, Article ID 1656938, 10 pages. 